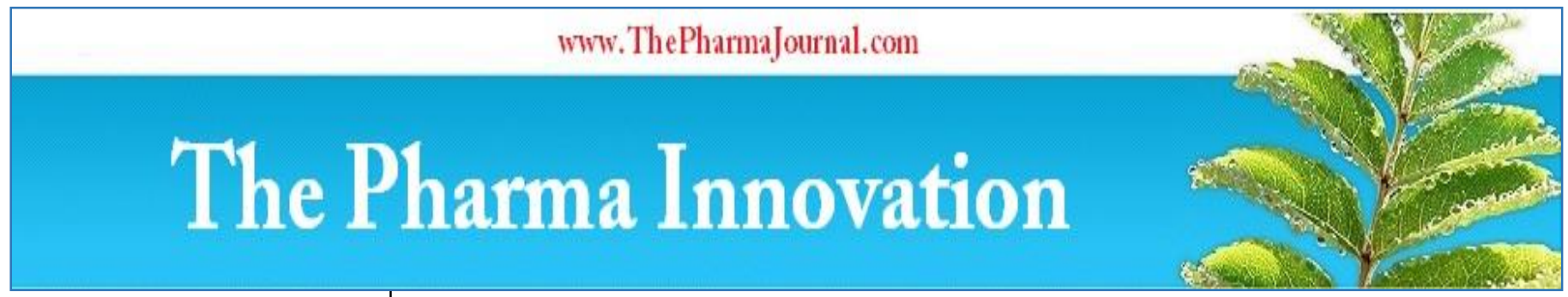

ISSN (E): 2277- 7695

ISSN (P): 2349-8242

NAAS Rating: $\mathbf{5 . 0 3}$

TPI 2021; 10(2): 185-188

(C) 2021 TPI

www.thepharmajournal.com

Received: 03-12-2020

Accepted: 05-01-2021

R Arunjyothi

Scientist, Home Science K.V.K

PVNRTVU, Mamnoor,

Warangal, Telangana, India

Dr. Afifa Jahan

Scientist, Food and Nutrition,

KVK-Palem, PJTSAU,

Nagarkurnool, Telangana, India

Corresponding Author:

R Arunjyothi

Scientist, Home Science K.V.K

PVNRTVU, Mamnoor,

Warangal, Telangana, India

\title{
Effect of Nutritional intervention in ameliorating Anemia among adolescent girls of rural Telangana state
}

\section{R Arunjyothi and Dr. Afifa Jahan}

DOI: $\underline{\text { https://doi.org/10.22271/tpi.2021.v10.i2c.5651 }}$

\section{Abstract}

The prevalence of anemia in Telangana state is very high. Adolescence age (10-19) years are considered most vulnerable age to anemia. The reasons are because of increased iron requirements related to rapid growth and menstrual loss which severely impairs the physical and mental development. During problem identification survey in the village, adolescents highlighted fatigue, body pains and weakness as the general prevailing problems among them.

The aim of the Present study was to assess the impact of intervention on anemia and diet pattern of adolescents in different Telangana zones. Purposive method was followed and 30 adolesent girls. 15 from southern Telangana zone (Nagarkurnool district) other 15 from central Telangan zone. Adolescent girls were tested for $\mathrm{Hb}$ levels and once ascertained with low $\mathrm{Hb}$ levels intervention programme as frontline demonstration was proposed. Sample comprised from low socio economic group working as seasonal agricultural labors involved in crop harvest activities. Pre intervention the samples were well informed and ethical committee consent was taken before the blood test. Hemoglobin meter was used by trained auxiliary midwifery in examining the Hb levels.

Diet Patten was assessed by food consumption format and one day recall method. Intervention of finger millet/ Ragi laddu of 65gm each @ 2 per day for a period of 12 week is provided to the sample. Nutrition education programme on importance of balance diet, and low cost recipes demonstration was also include in the intervention programme. Post intervention assessment was done in the same manner as pre intervention.

Post intervention analysis revealed a difference of $1 \mathrm{gm} / \mathrm{dl}$ improvement of $\mathrm{Hb}$ levels among adolescent. With the Improvement in the $\mathrm{Hb}$ levels majority of the sample slide from moderate anemic to mild anemic. One day recall method at pre intervention revealed that $21 \%$ of the adolescents consumed only 2 meals a day while $79 \%$ of them consumed 3 meals a day and all of them had tea twice a day.

The diet pattern at post intervention observed an increase in the portion and frequency of food consumption and also included snack items made of whole grams and millets at low cost which was missing earlier in their diet. Improvement in the $\mathrm{Hb}$ levels clearly indicated the positive effect of nutritional intervention. Apart from the supplementary nutrition, nutrition education programme and demonstration of low-cost nutritive diet might have created awareness among the group in enriching their diet pattern. This clearly indicates the low awareness level of the house holders on importance of nutrition and portion consumption as main cause for their poor health status.

Keywords: Anemia, finger millet/ragi ladoo, hemoglobin $(\mathrm{Hb})$, dietary consumption

\section{Introduction}

Anemia was a mild public health problem among young adolescents gobally. Nutritional and social determinants were identified as predictors, warranting interventions to reduce the risk of anemia among this critical age group (Zhu et al., 2021) ${ }^{[9]}$. Adolescence age is a critical period of growth, reproductive maturation, and developmental transitions which demands increased nutritional intake and therefore makes adolescents more vulnerable to nutritional deficiencies (Fuhrmann, 2015) ${ }^{[3]}$ Adolescents as described by the United Nations as those between the ages of 10 and 19, are 1.2 billion in number in world today, constituting 18 percent of the world's population. More than half of all adolescents live in Asia. Nearly $90 \%$ of adolescents live in low- and middle-income countries (LMICs) where under nutrition, including anemia and micronutrient deficiencies is a public health problems (Christian, 2018) ${ }^{[2]}$.

In absolute numbers, India is home to more adolescents- around 243 million-than any other country. Adolescents are the future generation of any country and their nutritional needs are critical for the well being of society. Adolescent girls are more vulnerable to anemia because of increased iron requirements related to rapid growth and menstrual loss and also inadequate 
dietary intake resulting in deficiency of nutrients especially iron. Prevalence of anemia among girls $(\mathrm{Hb}<12 \mathrm{gm} / \mathrm{dl})$ is alarmingly high. As per the reports 56 percent of adolescent girls were anemic, National Family Health Survey-3 (20052006) Ministry of Family Welfare, Government of India.

Inadequate nutrition during adolescence can have serious consequences throughout the reproductive life and beyond. Very often, in India girls get married and pregnant even before the growth period is over, thus doubling the risk for anemia (Chatterjee, 2008) ${ }^{[1]}$. A high prevalence of anemia among adolescent girls was found, with higher low economic strata. It was seen that anemia affects overall nutritional status of adolescent girls. The problems of adolescents are multi dimensional in nature and requires holistic in approach. Some of the problems faced by adolescents are anorexia nervosa, micronutrient deficiency, emotional problems, behavioral problems, substance abuse, identity and academic problems (Siddharam et al. 2011) ${ }^{[6]}$. Extensive studies on anemia reported that prevention of both iron deficiency and anemia requires measures that increase iron intake through food based approaches, namely dietary diversification and food fortification with iron; iron supplementation and improved health services and sanitation. Hence present study aims to accesses the effect of nutritional Intervention on hemoglobin levels and diet pattern of adolescents girls involved in agricultural and allied activities through a front line demonstration.

\section{Materials and Methods}

Study Area: Two districts namely Warangal district of central Telangana zone and Ngarkurnool district of southern Telangana zone were selected.

Study subject: Adolescent girls of 14-19 years who were actively involved in agriculture and allied activities, and whose hemoglobin levels were less than $12 \mathrm{mg} / \mathrm{dl}$ were selected.

Sample size and sampling technique: Present study included 30 adolescent girls purposively selected from two districts of rural Telangana state.

Data collection: The study was carried out during 2018-2020 in two districts of rural Telangana state-Warangal District of central Telangana zone and Nagarkurnool district of southern Telangana Zone. Help from Anganwadi workers is taken in identification of adolescents and in organizing group meetings with the parents of selected adolescent girls. Investigator contacted subjects and their mothers personally and the objective and nature of the study was explained and consent was sought to carryout survey and blood test to access the $\mathrm{Hb}$ levels. Help from Auxiliary Midwifery was sought in accessing the $\mathrm{Hb}$ levels during pre and post intervention. Hemoglobin estimation was obtained by cyan method. The severity of anemia was classified on the basis of WHO recommended as per table no I.

Table 1: WHO recommended HB levels

\begin{tabular}{|c|c|c|}
\hline S. No & HB levels & Classifications \\
\hline 1. & $\mathrm{Hb}<7 \mathrm{gm} / \mathrm{dl}$ & severe anemia \\
\hline 2. & $\mathrm{Hb} 7-10 \mathrm{gm} / \mathrm{dl}$ & moderate anemia \\
\hline 3. & $\mathrm{Hb} 10-12 \mathrm{gm} / \mathrm{dl}$ & mild anemia \\
\hline 4. & $\mathrm{Hb}>12 \mathrm{gm} / \mathrm{dl}$ & non anemic \\
\hline
\end{tabular}

A semi structured interview schedule was administered to study the subjects and the responses were recorded by the investigator. The questionnaire included the age, religion, family income, self earnings, history of illness, type of family, food habits and health information such as clinical signs of anemia height and weight of the subjects were included. To access the dietary pattern one day recall method format and food consumption checklist were used to know portion consumption and frequency of usage of the varied food items over a period of time. Post intervention assessment was done in the same manner as pre intervention.

\section{Intervention}

Nutrition intervention includes two components 1. Supplementation of nutritive diet and 2. Nutritional education.

\section{Supplementation of nutritive diet}

Low cost nutritive Ragi laddu of $65 \mathrm{gm}$ each with a composition of $30 \mathrm{gm}$ Finger millet, $20 \mathrm{gm}$ jaggery, $10 \mathrm{gm}$ of peanut $10 \mathrm{gms}$ of dates and $5 \mathrm{gm}$ of ghee was used as nutritional intervention. Nutrient composition of Ragi laddu each of $65 \mathrm{gm}$ consists approximately $119.51 \mathrm{mg}$ of calcium, $4.92 \mathrm{gm}$ of proteins, and $1.5 \mathrm{mg}$ of iron. The selected sample of adolescent girls were provided with 2 laddus each day for a period of 12 weeks ( 3 months) and tested for $\mathrm{Hb}$ levels.

Method of preparation of supplementation (Finger millet/ Ragi Ladoo): Pre preparation of Finger millet ladoo includes removal of stones and other dust and a thorough wash. They were soaked in water overnight and then tied into a cotton cloth for sprouting. After a day the sprouted Finger millet were sundried thoroughly and grinded as powdered. Grinded Finger millet powder was roasted in ghee for few minutes and added to roast peanut powder along with dates chopped into small piece. Cardamom powder for aroma was added. Once the jaggery was set to boiling temperature ie. Little less of one thread consistency, the Finger millet mixture is added to the syrup and round moulds (laddus) were made when the mixture is still hot.

\section{Nutrition education}

Under nutrition education the awareness camps and drama plays were conducted. Every week group meetings were conducted. Diet counseling's for iron and folic acid rich diets were given every week. Diet charts were made to ensure locally available low cost nutritive foods included in diet. Method demonstration of preparation of iron rich low cost recipes are given once in week to mother and adolescent girls. Mitigation of nutrient loss during cooking process, personal hygiene and sanitation was included.

Data analysis: The SPSS software was used for the analysis of the data.

The sample selected constituted in the age range of 14-19 years and were found moderately anemic with $\mathrm{Hb}$ levels $7>9$ $\mathrm{mg} / \mathrm{dl}$. These adolescents were school dropouts involved in as seasonal agricultural laboures in crop harvest activities and their parents were also unskilled agricultural laborers. Sample belonged to nuclear families with an average family size comprised of 5 members and were from low socio economic group working with an average family income of Rs. $<1,50$, 000 per annum and the selected samples individual income range from Rs. 10,000 $-15,000$ per annum.

Table II reveals that the selected sample was moderately 
anemic at pre intervention while an improvement of $1 / \mathrm{gm} / \mathrm{dl}$ $\mathrm{Hb}$ level is observed post intervention. With the improvement in $\mathrm{Hb}$ levels majority of the sample slide from moderate anemic to mild anemic.

Table 2: Hemoglobin levels of adolescent girls at pre and post intervention.

\begin{tabular}{|c|c|c|c|}
\hline \multicolumn{4}{|c|}{ Hemoglobin levels of the sample pre and post intervention } \\
\hline Age in years & Number & H b levels Pre intervention & H b levels Post intervention \\
\hline $14-16$ & 10 & $6-8$ & $8-9$ \\
\hline $17-18$ & 10 & $8-9$ & $10-12$ \\
\hline $18-19$ & 10 & $7-8$ & $9-10$ \\
\hline
\end{tabular}

The reasons for high incidence of anemia among the adolescents girls are increased iron requirements because of growth, menstrual loss, discrepancy between high iron need for hemoglobin formation and low intake of iron containing food, erratic eating habits, dislike for foods which are rich in iron like given leafy vegetables and iron absorption inhibition in food.

Results clearly indicate that intervention programme had positive effect on the hemoglobin levels of the sample. sample have also expressed that the general fatigue, physical pain and body aches reported pre intervention have reduced and were feeling much better and active at post intervention. Adequate calcium, protein and iron requirement provided by the Finger millet/Ragi laddu on regular basis has helped in the enhancement of $\mathrm{Hb}$ level and physical betterment among adolescents.

\section{Diet Pattern}

The diet pattern was collected through 24hours diet recall method. The data collected revealed that majority, $80 \%$ of the sample were non vegetarians while $20 \%$ were reported to be vegetarians by choice. However egg was reported to be consumed by all. With regard to frequency of having meals $79 \%$ of them has 3 meals a day while $21 \%$ of the reported of having just 2 meals a day. Mid evening meal or Snack item in their diet was absolutely missing. However all the sample has reported of having tea twice in a day after breakfast and evening.

According to Ranganath 2015, that majority of the girls in rural areas skipped breakfast and consumed high quality of Tea and Coffee. Interestingly, it was observed that the samples who are involved regularly in the agricultural activities were having 3 meals a day while the sample that were not regular to work were having only 2 meals a day and observations further revealed that the sample having only 2 meals a day had hemoglobin levels less than $<8 \mathrm{mg} / \mathrm{dl}$. The reason according to the data collected quoted by some of the subjects were no work, less income, family expenditure, low agricultural produce after farming due to climate changes, health issues and medical expenditures due to frequency of illness.

The portion consumption of foods per day revealed that the consumption of pulses, green leafy vegetables, and meat and milk products was just $50 \%$ to the RDA for adolescents. Sugar and oil were consumed in adequate quantities but low quality. Only cereal consumption was $80 \%$ to RDA that too concentrated only on rice item. One portion of pulses and one portion of milk were reported to be consumed while, 2 portions of pulses and 3 portions of milk were recommended respectively. Roots \& tubers and green leafy vegetables were consumed 50 percent of recommendations. Majority of the sample $(80 \%)$ had no fruit is their diet pattern and consumption of rice is approximately of about $150 \mathrm{gm}$ of cooked rice $30 \mathrm{gm}$ of cooked pulses, $20 \mathrm{gm}$ of cooked vegetables and 5-10gm of pickles or chutney made of some vegetables. Milk products like curds or buttermilk was completely absent in both the districts of Telangana state. Consumption of adequate fat in the diet is because of the psychology that more of oil in preparation of vegetables and curries enhances its taste was reported. Similarly consumption of sugar with1/3 portion of milk in tea is reason for its adequacy.

Observations at household level revealed that the table spoons (10-15 gms) capacity were used as serving spoons for vegetables and other curries. This indicates the ignorance of the subjects and their family members on essential portion consumption.

Another reason also reported by the subjects was the silent discrimination of girls observed at family level by mothers with regard to portion serving of vegetables, curries or meat items preferably to the male members of the family in both the districts of Telangana state studied. Food consumption check list revealed that cereal, pulses, oil and milk products were consumed daily, while roots and tubes were consumed one in a week which included only potato and colocasia. Green leafy vegetables and meat products fared up one in a week consumption list, fruits were occasionally consumed and consumption of millets was almost negligible in their diet. Interestingly adolescent girls have reported to have consumed all kind of vegetables which include Brinjal, Ladies Finger, Karela, Peas, Beans, and Tomato etc. Therefore different variety of vegetables every other day and are commonly available in the market. Most of the meat product included chicken compared to mutton and fish once in a month or only during festivals. Egg was found consumed twice in a week.

At post intervention a notable difference in the consumption of food items was observed among adolescents. Majority of the adolescents have shown interest in having breakfast made of cereal and pulses combination. Inclusion of fruits twice in a week was noted which was earlier neglected. Majorly inclusion of low cost fruits like gooseberries/Amla, Guva and citrus fruit was reported as suggested by the scientist in nutrition education camps. Post intervention, it was observed that millets like Finger millet/Ragi, sorghum/Jowar were included in their weekly diet. Traditional snack items made of whole grams of Bengal, black gram, chickpea, maize and ground nut were prepared at home which was missing in the diet pattern pre intervention. This might be because of their awareness on importance of evening meal or snack item in their diet and also the advantage of millets usage. Another reason is that the millets are more suitable in making traditional snack items. Mother has also expressed satisfaction over inclusion of snacks in their diet and also interested in revival of the preparing recipes with local available nutritional ingredients which is economical and affordable.

\section{Conclusion and recommendations}

Improvements in the $\mathrm{Hb}$ levels clearly indicated the positive 
effects of nutritional intervention. The supplementation of iron rich Finger millet made with jaggery and dates also has positive impact on $\mathrm{Hb}$ levels. The study reveals poor awareness levels among adolescent families with regard to nutritional requirements, their availability and portion consumption for maintaining of the health. Though there might be various factors that contribute to the prevalence of low $\mathrm{Hb}$ levels, but the present intervention has helped to narrow down this major health problems through intervention of nutrition diet and nutrition education. Effectiveness of the nutrition intervention proves that there is an urgent need of nutrition education among the adolescents for their better future and healthy nation. Therefore Government and NGOs working for adolescents need to force on nutritional education programmes and supplementation of nutrition for adolescents. The adolescent girls were recommended to avoid the immediate consumption of tea after meals like breakfast etc. They were advised to consume it before one hour or after one hour meals to prevent antinutritional effects for iron absorption and also recommended to consume vitamin $\mathrm{C}$ rich diet for proper iron absorption. The locally available vitamin $\mathrm{C}$ fruits in Telangana state with low cost like Guava and gooseberry along with citrus fruits were recommended.

\section{References}

1. Chatterjee R. Nutritional needs of adolescents paediatrics today 2008;3:110-4.

2. Christian P, Smith ER. Adolescent undernutrition: global burden, physiology, and nutritional risks. Ann Nutr Metab 2018;72(4):316-28.

3. Fuhrmann D, Knoll LJ, Blakemore S. Adolescence as a sensitive period of brain development. Trends Cogn Sci 2015;19(10):558-66.

4. Ranganath JS, Ipsita Debata. Assessment of diet and anemia status among adolescent girls in urban Bangalore, International Journal of Inter Disciplinary Studies (IJIMS) 2005;2(11):36-42.

5. Shanti Devi, Vidya Deswal, Ramesh Verma. Prevalence of anemia among adolescent girls: A school based study, International Journal of Basic and Applied Medical Sciences ISSN: 22 77-2013.

6. Siddharam SM, Venkatesh GM, Thejeshwari HL. A study of anemia among adolescent's girls in rural areas of Hassan district, Karnataka, South India, International Journal of Biological and Medical Research 2011;2:9224.

7. Jaya Chandra Naidu T, et al. A study of anemia among adolescent girls in Tirupati rural and urban areas through government high schools, Journal of Biological and Scientific Opinion 2015;3(3).

8. World Health Organization. Manual of Technologies for a Health Laboratory ( $2^{\text {nd }}$ edn) WHO 2003.

9. Zhu Z, Sudfeld CR, Cheng Y, et al. Anemia and associated factors among adolescent girls and boys at 1014 years in rural western China. BMC Public Health 2021;21:218. https://doi.org/10.1186/s12889-021-10268-

$\mathrm{Z}$ 